\title{
Fronto-Temporo-Zygomatic Approach for Orbital Apex and Infratemporal Fossa
}

\author{
Kishan P. Morwani ${ }^{a}$, Gaurav Ahluwalia ${ }^{\mathrm{b}, \mathrm{c}}$
}

\begin{abstract}
Modified fronto-temporo-zygomatic approach is a relatively direct and less time-consuming approach to infratemporal fossa and orbital apex. This approach has a smaller learning curve and sutures are hidden in hairs, hence beneficial to both the patient and the surgeon.
\end{abstract}

Keywords: Musculoperiosteal flap; Optic disc; Orbital apex; Infratemporal fossa approach; Fronto-temporo-zygomatic approach

\section{Introduction}

The infratemporal fossa (ITF) is a potential space bounded superiorly by the temporal bone and the greater wing of the sphenoid bone, medially by the superior constrictor muscle, the pharyngobasilar fascia, and the pterygoid plates, laterally by the zygoma, mandible, parotid gland, and masseter muscle, anteriorly by the pterygoid muscles, and posteriorly by the articular tubercle of the temporal bone, glenoid fossa, and styloid process.

ITF contains internal carotid artery, internal jugular vein, cranial nerves (IV to XII), internal maxillary artery, pterygoid venous plexus, and pterygoid muscles. The ITF communicates with the middle cranial fossa via carotid canal, jugular foramen, foramen spinosum, foramen ovale, and foramen lacerum. Medially, the ITF communicates with the pterygopalatine fossa via the pterygomaxillary fissure, which is contiguous with the inferior orbital fissure and, thus, the orbit [1].

Patients with ITF tumors can present with various symptoms depending on the structures affected. Mass effects, Eustachian tube dysfunction, trismus, and cranial neuropathies are

Manuscript accepted for publication June 24, 2016

${ }^{a}$ Department of Otorhinolaryngology, Dr. Balabhai Nanavati Hospital, Mumbai, India

bAhluwalia Superspeciality Hospital, Raipur, Chhattisgarh, India

${ }^{\mathrm{c} C}$ Corresponding Author: Gaurav Ahluwalia, Ahluwalia Hospital, Nemichand Street, Gunj Para, Near Prabhat Theatre, Raipur 492001, Chhattisgarh, India. Email: drgauravahluwalia@gmail.com

doi: http://dx.doi.org/10.14740/jcs298e common.

In 1961, Fairbanks-Barbosa was the first to report an ITF approach, indicated for advanced tumors of the maxillary sinus [2]. Transtemporal approaches described by Fisch, preauricular approaches described by Schramm and Sekhar, and transmaxillary approaches described by Terz, Janecka, and Cocke validated the efficacy of and indications for this technique, and provided the framework for other modifications [35]. Recently, transnasal endoscopic and endoscopic-assisted approaches have been added to the armamentarium of skull base surgeons.

\section{Case Report}

A 36-year-old male visited the outpatient department of otorhinolaryngology with visual defect in right eye for last 3 months. Vision was gradually decreasing, along with diplopia and increasing proptosis in the same eye and presently there was no light perception for last 20 days in the right eye. There was no headache and vomiting (Fig. 1).

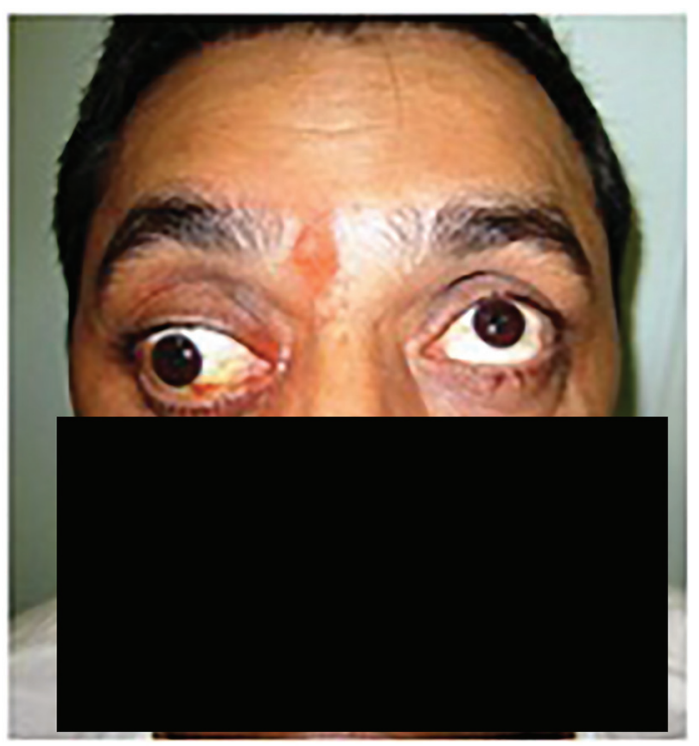

Figure 1. Proptosis of right eye and fixed eyeball seen when the patient came to OPD, with dilated pupil. This finding was correlating with poor vision of the patient from the same eye. 


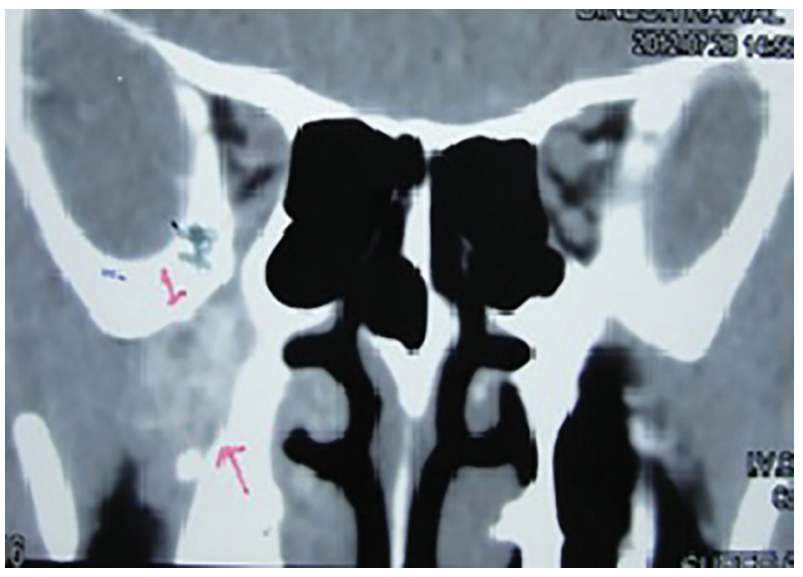

Figure 2. Plain coronal view computed tomography of orbit and paranasal sinuses showing infratemporal fossa infiltration and widening of the space.

He had already received oral steroids (prednisolone 50 mg tapering over 1 month) and anti-tubercular drugs by physicians before reaching us, though temporarily benefited but symptoms worsened soon.

On detailed examination, he had fixed right eyeball with no light perception and dilated and fixed pupil in the proptosed eye. Fundus showed disc edema, small hemorrhagic spots, and tortuous dilated blood vessels. Left eye and facial movements were normal. Magnetic resonance imaging revealed a soft tissue lesion occupying ITF, cavernous sinus and orbital apex (Figs. 2 and 3).

A hair line incision was made, skin flap, superficial temporalis facia and musculo-periosteal flap were elevated and fronto-temporo-zygomatic en bloc craniotomy was done with inferior based single muscle flap to approach ITF and orbital apex, which was later fixed with titanium screws and curved plates (Figs. 4-10).

Post-operatively, vision of the right eye gradually improved drastically as also evident by the resolved edema of the optic disc when compared to its preoperative status. Histopathology was reported as chronic non-specific inflammatory le-

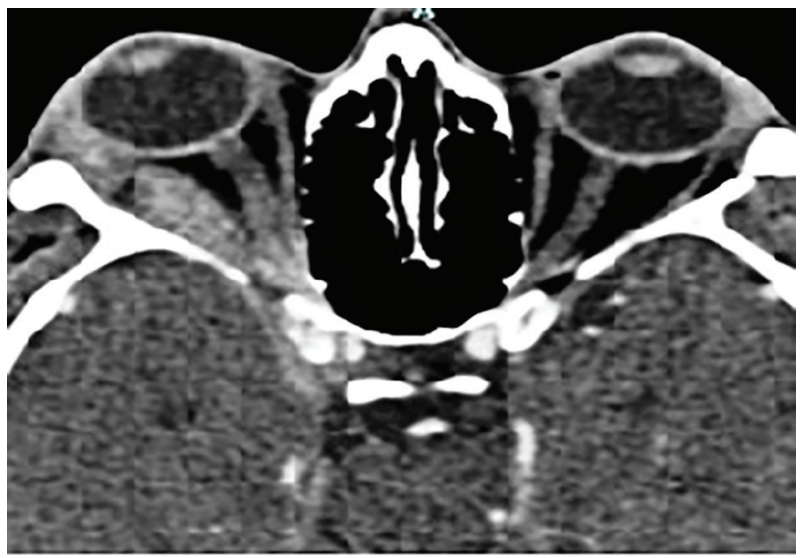

Figure 3. Magnetic resonance imaging plain axial view showing orbital apex edema infiltration of right eye, edematous lateral rectus muscle.

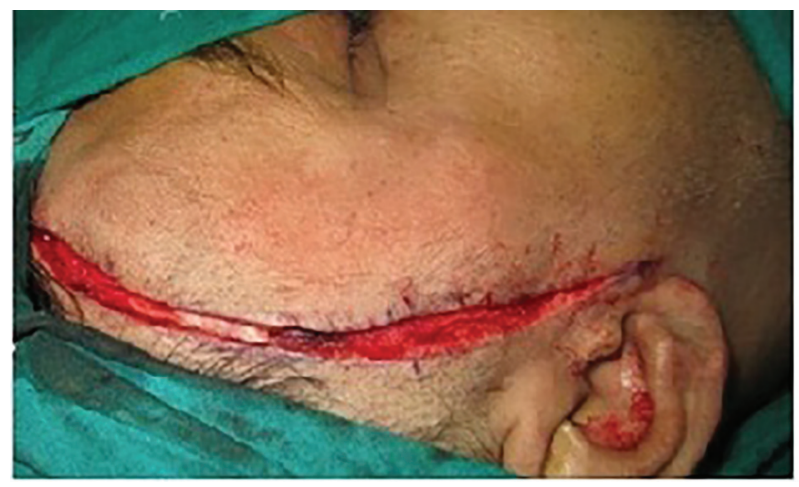

Figure 4. Hairline coronal incision. The advantage of this incision is that it hides in the hairs and so is cosmetically appealing.

sion and started on cyclophosphamide which completely cured the lesion (Figs. 11 and 12).

\section{Discussion}

An ITF approach is a complex procedure that involves significant time, effort, and cost. There are many infratemporal approaches described with their advantages over others and limitations.

An endoscopic endonasal ITF approach may provide the access required for the resection of a tumor, or it may be adjunctive to other approaches, such as transcranial-subtemporal, Le Fort I, transmaxillary, or anterior subfrontal approaches [6].

Indications for a preauricular approach include tumors that originate in the ITF and intracranial tumors that originate at the anterior aspect of the temporal bone or greater wing of the sphenoid bone and that extend into the ITF. The preauricular approach provides inadequate exposure for the resection of tumors that invade the tympanic bone and does not provide adequate access to the intratemporal facial nerve or jugular bulb [7].

The post-auricular approach and Fisch modifications have been designed to expose and resect lesions that involve the

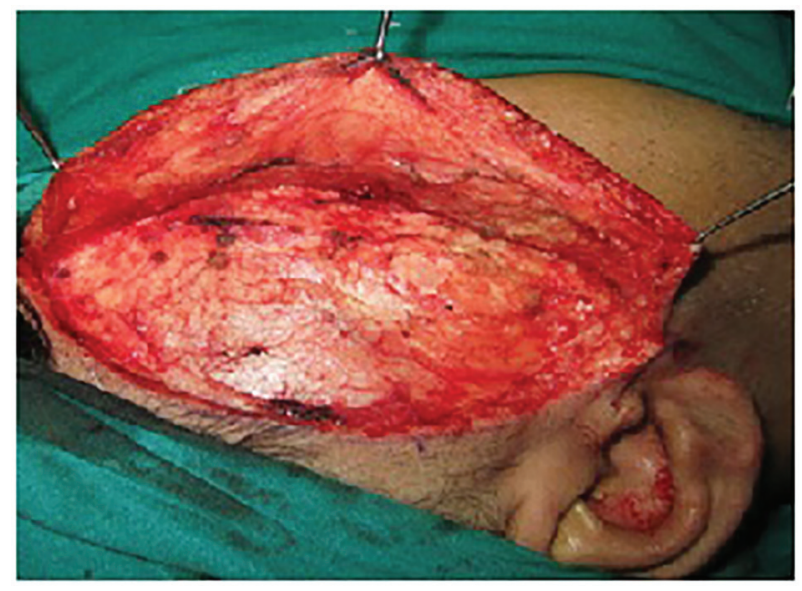

Figure 5. Skin flap elevated over the superficial temporalis fascia. 


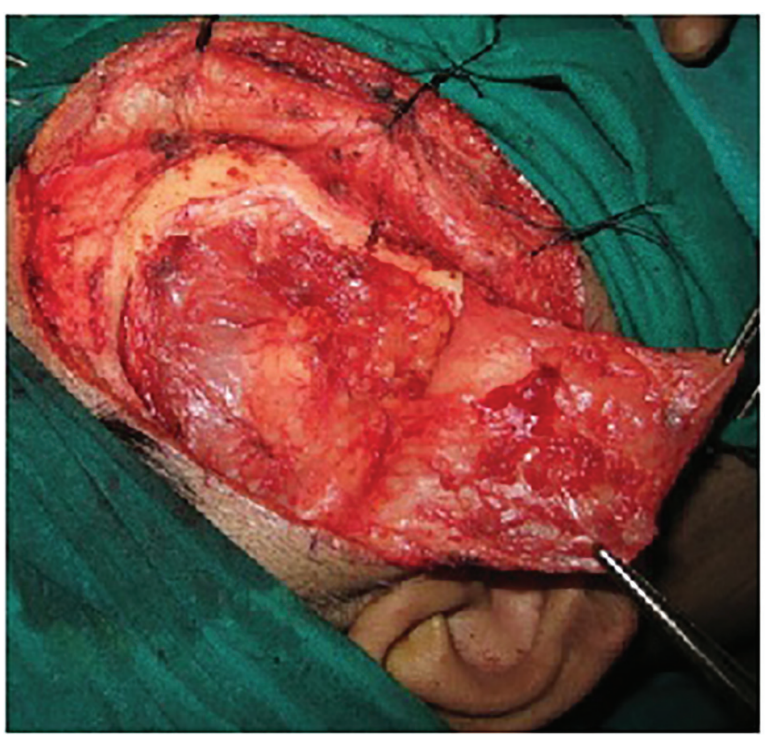

Figure 6. Subgaleal pad of fat with superficial temporalis fascia layer elevated.

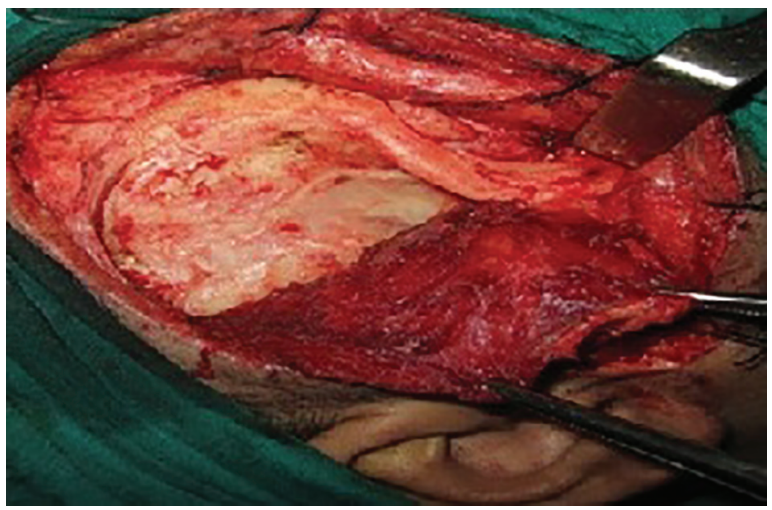

Figure 7. Musculoperiosteal flap elevated to expose the bony frame work. Muscle is inferiorly displaced.

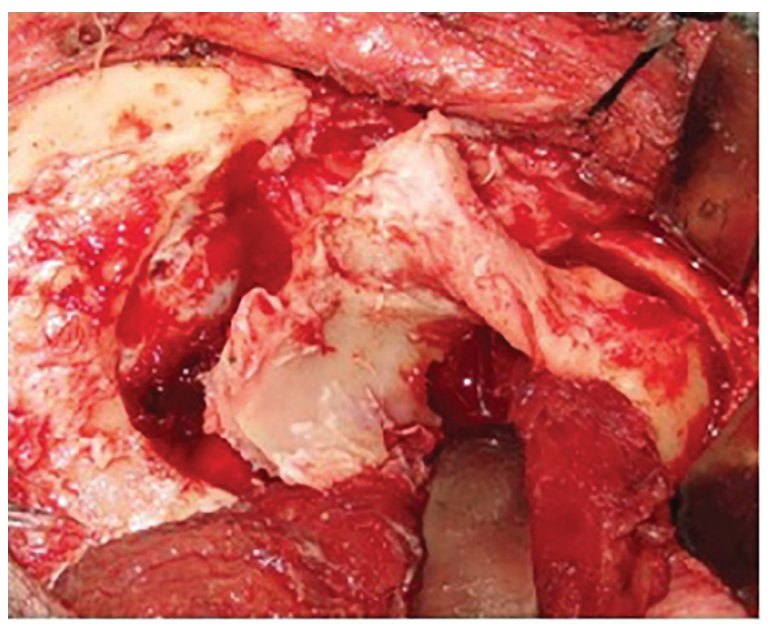

Figure 8. En bloc craniotomy done with inferiorly based single muscle flap.

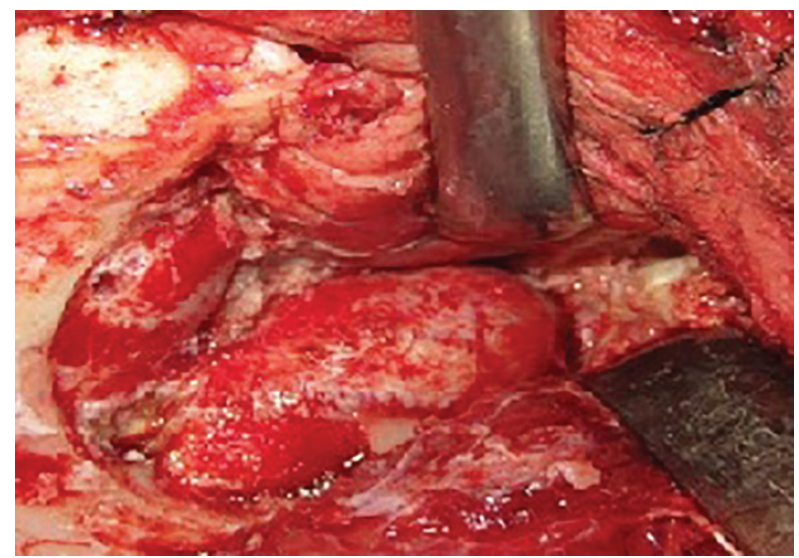

Figure 9. Orbital apex lesion.

temporal bone and that extend into the ITF.

The transfacial approach is best used to resect sinonasal tumors that require maxillectomy and that invade the ITF, the masticator space, or the pterygomaxillary fossa and for tumors of the nasopharynx extending into the ITF. However, the authors reserve its use for cancers of the antrum that extend into the ITF.

A transorbital approach may be used to complement the exposures obtained with one of the previous approaches, thus enhancing the exposure of the orbital apex and cavernous sinus [8].

The type D approach is a preauricular ITF approach that uses orbitozygomatic osteotomies and resection of the floor of the middle fossa to expose the medial middle cranial fossa without a lateral temporal craniotomy. During the type D approach, the middle ear and Eustachian tube are not obliterated, and conductive hearing is not sacrificed. In addition, the intratemporal facial nerve is not rerouted, and the petrous ICA is not fully exposed. Subtype D1 addresses tumors of the anterior ITF, while the subtype D2 is designed for lateral orbital wall lesions and high pterygopalatine fossa tumors. Although these preauricular approaches do not include a temporal craniotomy, the floor of the skull base can be drilled away to allow full ac-

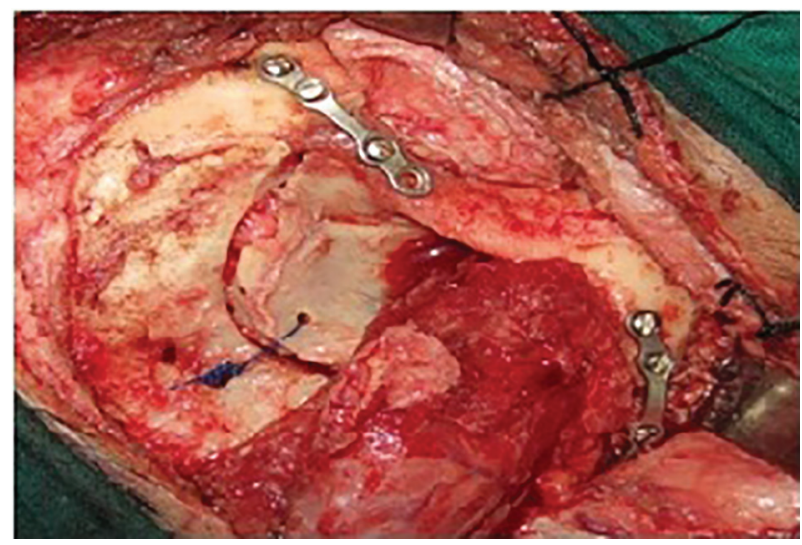

Figure 10. Post-surgery, repositing back the en bloc craniotomy and fastening the assembly with titanium screws and plates. Titanium has a property of osseo-integration. 

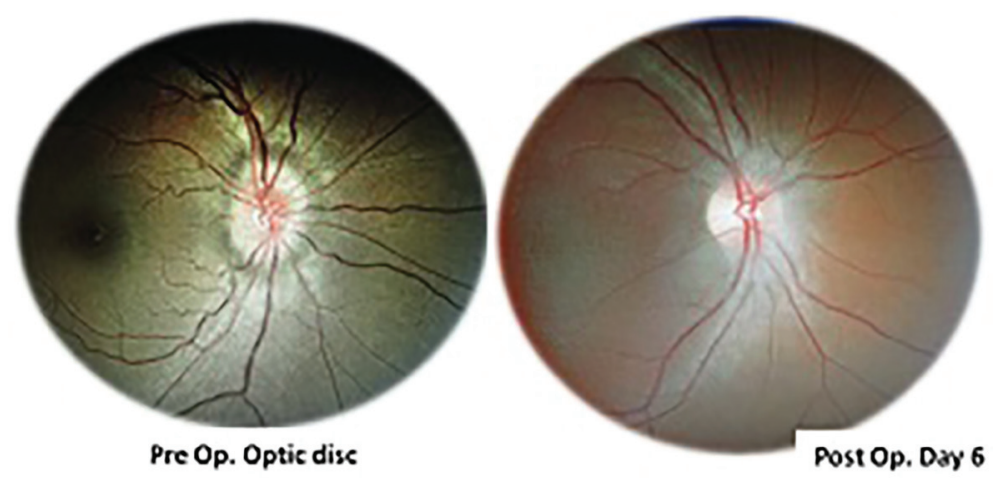

Figure 11. Pre- and postoperative optic disc pictures. Preoperatively optic disc was edematous dull. Six days postoperatively, the edema subsided and disc appeared normal.
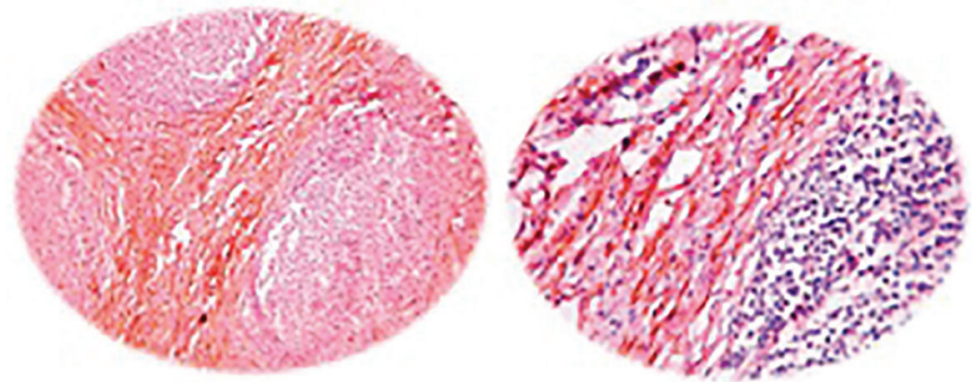

Figure 12. Histopathology slide reported as chronic non-specific inflammatory infiltrate/pseudotumor.

Table 1. Various Modified Trans-Facial Pre-Auricular Approaches to Orbital Apex and Infratemporal Fossa

\begin{tabular}{|c|c|c|}
\hline Name & Approach & Lesions \\
\hline $\begin{array}{l}\text { Pellerin } \\
\text { et al }\end{array}$ & Orbito-fronto-mallar approach & $\begin{array}{l}\text { Orbital } \\
\text { meningioma }\end{array}$ \\
\hline $\begin{array}{l}\text { Hakuba } \\
\text { et al }\end{array}$ & $\begin{array}{l}\text { Orbito-zygomatic ITF approach } \\
\text { Fronto-orbito-temporal } \\
\text { craniotomy. Three } \\
\text { separate bone flaps }\end{array}$ & $\begin{array}{l}\text { Cavernous } \\
\text { sinus lesions }\end{array}$ \\
\hline Frazier & Concept of removing orbital rims & $\begin{array}{l}\text { Improved } \\
\text { exposure of } \\
\text { skull base }\end{array}$ \\
\hline $\begin{array}{l}\text { Delashaw } \\
\text { et al }\end{array}$ & $\begin{array}{l}\text { Fronto-temporal flap }+ \\
\text { superior and lateral orbital rim } \\
+ \text { frontal sinus. Zygomatic } \\
\text { arch removed separately }\end{array}$ & $\begin{array}{l}\text { Anterior } \\
\text { fossa, middle } \\
\text { fossa, orbit, } \\
\text { cavernous sinus }\end{array}$ \\
\hline McDermott & $\begin{array}{l}\text { Removal of fronto-temporal } \\
\text { and orbito-zygomatic } \\
\text { bone flaps separately }\end{array}$ & \\
\hline Al Mefty & $\begin{array}{l}\text { Incorporated superior orbital } \\
\text { ridges with pterional craniotomy }\end{array}$ & \\
\hline $\begin{array}{l}\text { Morwani } \\
\text { et al }\end{array}$ & $\begin{array}{l}\text { Modified fronto-temporo- } \\
\text { zygomatic approach }\end{array}$ & $\begin{array}{l}\text { Limited disease } \\
\text { in ITF, lateral } \\
\text { orbit and } \\
\text { orbital apex }\end{array}$ \\
\hline
\end{tabular}

cess to the ITF.

In our modification of the preauricular approach, temporal craniotomy was also done and retracted inferiorly as a single muscle based flap. Hence the exposure is wider and entire ITF and orbital apex can be assessed (Table 1).

\section{Conclusion}

Modified fronto-temporo-zygomatic approach is a direct and less time access to ITF and orbital apex. It is cosmetically superior as the incision line merges with the hair line. It gives a wider access to the ITF structures. The procedure is simple with smaller learning curve as compared to other ITF approaches.

\section{References}

1. Ricardo L Carrau, Arlen D Meyerset et al. Infratemporal Fossa Approach Treatment \& Management. Feb 01, 2016, Medscape.

2. Barbosa JF. Surgery of extensive cancer of paranasal sinuses. Presentation of a new technique. Arch Otolaryngol. 1961;73:129-138.

3. Sekhar LN, Schramm VL, Jr., Jones NF. Subtemporalpreauricular infratemporal fossa approach to large lateral and posterior cranial base neoplasms. J Neurosurg. 1987;67(4):488-499. 
4. Janecka IP, Sen CN, Sekhar LN, Arriaga M. Facial translocation: a new approach to the cranial base. Otolaryngol Head Neck Surg. 1990;103(3):413-419.

5. Cocke EW, Jr., Robertson JH, Robertson JT, Crook JP, Jr. The extended maxillotomy and subtotal maxillectomy for excision of skull base tumors. Arch Otolaryngol Head Neck Surg. 1990;116(1):92-104.

6. Chan JY, Li RJ, Lim M, Hinojosa AQ, Boahene KD. Endoscopic transvestibular paramandibular exploration of the infratemporal fossa and parapharyngeal space: a minimally invasive approach to the middle cranial base. Laryngoscope. 2011;121(10):2075-2080.

7. Catalano PJ, Biller HF. Extended osteoplastic maxillotomy. A versatile new procedure for wide access to the central skull base and infratemporal fossa. Arch Otolaryngol Head Neck Surg. 1993;119(4):394-400.

8. Mishra A. Transorbital approach to infratemporal fossa: novel technique. J Laryngol Otol. 2011;125(6):638-642. 